\author{
EISSN:2706-7920 ISSN: 2077-4435 \\ DOI: $10.36632 / \mathrm{csi} / \mathbf{2 0 2 1 . 1 0 . 2 . 2 7}$ \\ Journal homepage: www.curresweb.com \\ Pages: 295-308
}

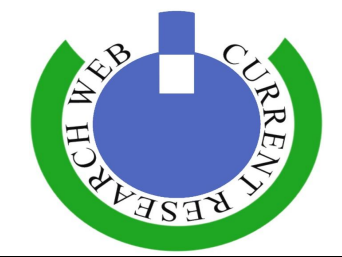

\title{
Nano Fertilizers, Their Role and Uses in Crop Productivity. A Review
}

\author{
A.I. Rezk ${ }^{1}$, A.B. El-Nasharty ${ }^{1}$, S.S. El-Nwehy ${ }^{1}$ and O.A. Nofal ${ }^{2}$ \\ ${ }^{I}$ Department of Fertilization Technology and ${ }^{2}$ Plant Nutrition Departments, Agricultural \& Biological \\ Research Division, National ResearchCentre (NRC), 33 El-Buhouth St., 12622 Dokki, Giza, Egypt. \\ Received: 15 March $2021 \quad$ Accepted: 20 April $2021 \quad$ Published: 30 April 2021
}

\begin{abstract}
Nano fertilizers (NFs) are an attractive alternative fertilizer in agriculture for improving growth parameters, yield, and quality of crops with increasing use efficiency of nutrients, minimizes fertilizers wastage and so the cultivation cost. The present paper aimed to supply an overview on the uses of nanofertilizers (NFs) in crops, highlighting their advantages and potential uses, and reviewing their effects under normal and environmental stress conditions. NFs are modified fertilizers which produced using nanotechnology by chemical, physical or biological methods to enhance their properties and composition, which positively affecting crop yields. Various studies have showed the benefits of using nanofertilizers instead of the conventional ones due to their highly specific surface area and smaller particles size which led to improving absorbent ability, controlled release kinetics and finally reaching to highest nutrient use efficiency, in addition to reducing the environmental pollution resources. Also, these nanometric fertilizers are superior to traditional fertilizers in the efficiency of their absorption (Nutrient Use Efficiency) and activation of the metabolic processes inside the plant due to the higher surface area of their molecules, use of less quantities with greater effectiveness and their supply to plants with their nutrients' needs for longer periods comparing to the traditional forms and positively improve the biochemical content of crop and its quality. In this concern, NFs can release their nutrients during longer period (40-50 days), while in 4-10 days only, synthetic fertilizers do so. Otherwise, after field application, conventional fertilizers, especially urea, lose around fifty percent of its nitrogen content. In other words, research have shown that, NFs release nutrients 12 times more slowly comparing to synthetic fertilizers which reflecting on increasing the yields and quality characteristics of crops. In conclusion, nanofertilizers in the form of nano materials through slow or controlled release mechanisms could support their active nutrients depending on plant requirement's and in the proper time, which finally reflects in improving the crops production.
\end{abstract}

Keywords: Nanofertilizers, synthetic fertilizers, crop production

\section{Introduction}

Modern farming is using high-quality agrochemicals. Global production, for instance, of industrial fertilizers reached 188.2 million tons in 2019 (FAO, 2020). Soon, the quantity of agrochemicals expected to rise to the level that can feed 9.6 billion people by 2050 . To achieve best growth and productivity of the plants, synthetic chemical fertilizers are used. In most cases, the artificial fertilizers used in intensive cultivation show low nutrients use efficiency (NUE) values (Guo et al., 2018). For instance, the NUE values are low by 30-35\%, 18-20\% and 35-40\% respectively for the three macronutrients; NPK (Husen and Iqbal, 2019), it means that more than $50 \%$ of fertilizers are lost by many ways, i.e., leaching, fixation, and hydrolysis.

To increase crop yields with declining nutrient efficiency values, this led to intensive use of synthetic fertilizers (Guo et al., 2018). However, this widespread use of artificial fertilizers will lead to significant environmental risks in the long term, such as air pollution, soil depletion, nutrient enrichment, and pollution of groundwater (Seleiman et al., 2020b). In addition, Low NUE values and

Corresponding Author: El-Nasharty A.B., Department of Fertilization Technology, Agricultural \& Biological Research Division, National Research Centre (NRC), 33 El-Buhouth St., 12622 Dokki, Giza, Egypt. Email: elnashartynrc@gmail.com 
increased environmental risks associated with increased use of artificial fertilizers have been a longterm obstacle to achieving sustainability in agriculture, concerning increasing the production costs and so lowers profit margins for farmers (Diatta et al., 2020). The main result of the low values of nutrients use efficiency are both larger release values of the nutrients from traditional fertilizers than their uptake by plants or change them to unavailable form to absorb by plants. Recently, Usman et al. (2020) state that by using new nanotechnology it can be convert the chemical fertilizers to NFs aiming to increasing their use efficiency and then supply a solution to agricultural problems.

The nanoparticle, which is the nutrient itself or the nutrients carrier, defined as a nano fertilizer (NFs).Nutrients inside or coated by nanomaterials are also termed NFs (DeRosa et al., 2010). On the bases of plant requirements, NFs are classified to macronutrients and micronutrients -NFs, and nanoparticles fertilizers (Chhipa, 2017). These "nano fertilizers" that have high values of both of surface area and adsorption ability as well as controlled-release process to specific sites. Nano structured fertilizers can increase NUE and exactly release their active contents according to crop requirements (Seleiman et al., 2020a, b). The purpose of this overview is to discuss role and uses of nano-fertilizers in crop.

\section{What is Nano Fertilizer?}

Nano Fertilizers are manufactured forms of conventional fertilizers or bulk materials of fertilizers or extracted from various parts of plants using various chemical, physical, mechanical, or biological methods with helping of nanotechnology for improving soil fertility and the agricultural productivity. In addition, Nanoparticles synthesized from whole bulk solids (Brunnert et al., 2006 and Singh and Kumar, 2017). Nel et al., (2006) stated that, in the nano-range, the physical and chemical properties of bulk solids differ. So, if phosphate rocks used in nanoform, this can lead to an increase in phosphorus availability for the plants due to inhibit soil fixation.

Nano-fertilizers have some specific properties that enable increased nutrient utilization efficiency. The important features are: 1- Nano-fertilizers have a smaller particles size (less than 100 $\mathrm{nm}$ ) which lead to an increase in the specific surface area and the number of particles per unit area and offer more opportunity for the nano fertilizer to come into contact to the plant system (roots and leaves) which leads to more penetration and absorption, i.e., high use efficiency of fertilizer. All of these facilitate different metabolisms and more photosynthesis in the plant system while consuming lesser amounts of fertilizers. 2- It has high solubility in various solvents such as water. 3- Fertilizer elements encapsulated in nanoparticles increase the availability of phytonutrients and thus, their uptake by crops.4-Zeolite-based nano-fertilizers can slowly release nutrients to the crop, which increases the nutrient availability for the crop despite the growth phase. Examples of nano fertilizers: Nitrogen-, Phosphorus-, Potash-, Zinc-, Iron-, Manganese-, Cupper-, Boron, Silica -Nano-Fertilizers and finally the Zeolite-based Nano-Fertilizers (nano porous zeolite), and Carbon Nano Tube.

\section{Properties of nano-fertilizers}

Each nano-fertilizer must be formulated to have all the desirable properties such as high solubility, stability, effectiveness, time control, enhanced target activity at effective concentration, minimal environmental toxicity with safe and easy administration and disposal (Torney et. al., 2007). Nano-fertilizers often hold nutrients and growth promoters that are encapsulated in nano polymers, chelates or emulsifiers (slow, targeted, and effective release becomes possible). In some cases, the nanoparticle itself can stimulate growth.

Glass (2003) and Naderi and Danesh - Shahraki (2013) reported some benefits related to the converted formulation of conventional fertilizers using nanotechnology as follow :a)The nano structured formula can allow the fertilizer to intelligently control the rate of nutrient release to match the style of plant uptake, b) Dispersion and solubility of the mineral micronutrients that cause the controlled release formulation, c) The nano form of mineral micronutrients can improve the solubility and distribution of insoluble nutrients in the soil, decrease soil adsorption and fixation, and increase bioavailability, resulting in an increase in nutrient absorption efficiency, d) The formula with nanostructure can increase fertilizing efficiency and nutrients absorption ratio by plant and save fertilizer resources. Kottegoda et al., (2011), synthesis of modified urea molecules from hydroxyapatite (HA) for the progressive release of nitrogen during plant growth. These nano fertilizers showed an initial blowing out and then slowly releasing nitrogen for up to 60 days of plant 
growth compared to commercial fertilizers which only for up to 30 days. The considerable amount of urea binding on the surface of HA is enabled by the wide surface area of HA. The close interaction of urea-containing HA nanoparticles leads to a gradual and regulated release of urea. Similarly, porous polymer-based nanoparticles can provide agrochemical compounds with an effective delivery mechanism that increases performance and economical usage. They also using porous $(150 \mathrm{~nm})$ nanosilica particles to trap urea, it was showed that 15.5 percent of urea was entered into the pores of the nanoparticles' and showed regulated release of urea in soil. In release period, the analysis showed that, at least a five-fold increase (Wanyika et al., 2012). Melanie et al., (2012) described the solubility process of zinc from the nano particles of zinc oxide and from zinc oxide particles coated on urea and mono ammonium phosphate fertilizers. They stated that the pellets of mono-coated ammonium phosphate had a faster dissolution rate.

\section{Comparison of Nano Fertilizers and Conventional Fertilizers}

Conventional Fertilizers are commonly applied to the crops as foliar spraying or broadcasting. However, one of the major factors that decide the mode of application is the final amounts of the fertilizers reaching to the plant. Practically, extremely low amounts of fertilizer (much below to minimum desired concentration) reach to the targeted site due to leaching, drift, runoff, evaporation, hydrolysis by soil moisture, and photolytic and microbial degradation. Ombodi and Saigusa (2000) found that $40-70 \%$ of nitrogen, $80-90 \%$ of phosphorus, and $50-90 \%$ of potassium content of applied fertilizers lost in the environment and could not reach to the plant which causes sustainable and economic losses. Hence, it is imperative that chemical fertilization is used optimally to meet the nutritional needs of the plants and to reduce the risk of environmental pollution. Accordingly, it may therefore also be desirable to test and use other fertilization techniques to support the requisite minerals for plant growth and yield production, as well as keeping the soil structure in good condition (Miransari, 2011).Nanotechnology has made it possible to study nano structured materials as fertilizer or controlled vectors for the construction of smart fertilizers as new facilities to improve NUE and reduce the costs (Chinamuthu and Boopati, 2009).

Table 1: Comparison of nanotechnology-based formulations and conventional fertilizers applications.

\begin{tabular}{clll}
\hline S.No. & Properties & Nano-fertilizers-enabled technologies & Conventional technology \\
\hline $\mathbf{1}$ & $\begin{array}{l}\text { Solubility and } \\
\text { dispersion of } \\
\text { mineral } \\
\text { micronutrients }\end{array}$ & $\begin{array}{l}\text { Nano-sized formulation of mineral } \\
\text { micronutrients may improve solubility and } \\
\text { dispersion of insoluble nutrients in soil, reduce } \\
\text { soil absorption and fixation, and increase the } \\
\text { bioavailability }\end{array}$ & $\begin{array}{l}\text { Less bioavailability to plants } \\
\text { due to large particle size and } \\
\text { less solubility }\end{array}$ \\
\hline $\mathbf{2}$ & $\begin{array}{l}\text { Nutrient uptake } \\
\text { efficiency }\end{array}$ & $\begin{array}{l}\text { Nano structured formulation might increase } \\
\text { fertilizer efficiency and uptake ratio of the soil } \\
\text { nutrients in crop production and save fertilizer } \\
\text { resource }\end{array}$ & $\begin{array}{l}\text { Bulk composite is not } \\
\text { available for roots and } \\
\text { decrease efficiency }\end{array}$ \\
\hline $\mathbf{3}$ & $\begin{array}{l}\text { Controlled release } \\
\text { modes }\end{array}$ & $\begin{array}{l}\text { Both release rate and release pattern of } \\
\text { nutrients for water soluble fertilizers might be } \\
\text { precisely controlled through encapsulation in } \\
\text { envelope forms of semi permeable membranes } \\
\text { coated by resin-polymer, waxes, and sulfur }\end{array}$ & $\begin{array}{l}\text { Excess release of fertilizers } \\
\text { may produce toxicity and } \\
\text { destroy ecological balance of } \\
\text { soil }\end{array}$ \\
\hline & $\begin{array}{l}\text { Effective duration } \\
\text { of nutrient release }\end{array}$ & $\begin{array}{l}\text { Nano structured formulation can extend } \\
\text { effective duration of nutrient supply of } \\
\text { fertilizers into soil }\end{array}$ & $\begin{array}{l}\text { Used by the plants at the time } \\
\text { of delivery, the rest is } \\
\text { converted into insoluble salts } \\
\text { in the soil }\end{array}$ \\
\hline \multirow{5}{*}{$\begin{array}{l}\text { Loss rate of } \\
\text { fertilizer nutrients }\end{array}$} & $\begin{array}{l}\text { Nano structured formulation can reduce loss } \\
\text { rate of fertilizer nutrients into soil by leaching } \\
\text { and/or leaking }\end{array}$ & $\begin{array}{l}\text { High loss rate by leaching, } \\
\text { rain off, and drift }\end{array}$ \\
\hline
\end{tabular}

These properties of nano fertilizers are based on their high both of surface-to-volume ratio, solubility, and specific targeting due to their small size, high mobility, and low toxicity (Sasson et al., 2007). Nano fertilizers or nanostructures can have effective on each of plant properties, release 
nutrients if necessary and therefore regulate plant growth and increase target activity (DeRosa et al., 2010 and Nair et al., 2010).

\section{Advantages of nano-fertilizers (NFs) over synthetic fertilizers}

Figure (1) shows how nano particles are encapsulated with nano materials which control the release of nutrients, according to plant requirements. This increases the NUE values of plants (Qureshi et al., 2018). Specifically, in 40 to 50 days, NFs will release their nutrients, while synthetic fertilizers can do only in 4 to 10 days. Accordingly, urea synthetic fertilizer loses more than $70 \%$ of its nitrogen content after field application, through leaching and volatilization (Kahrl et al., 2010).

\section{Slow release fertilizer/agrochemicals based on Nanotechnology}

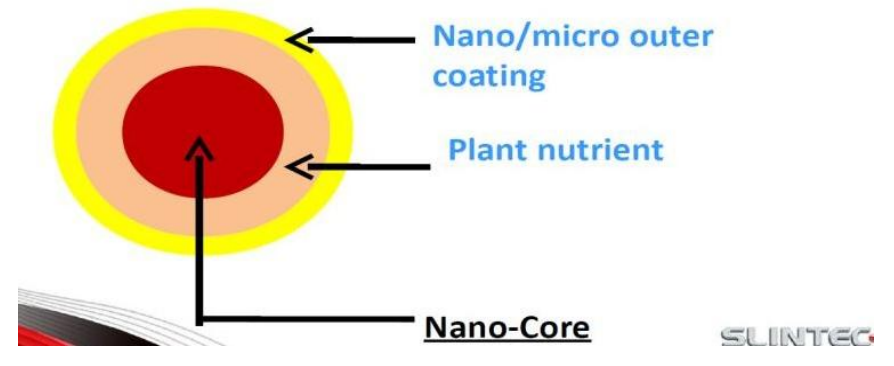

Fig. 1: Nutrient encapsulation by nano-micro coating- Coated with a thin nano-material layer.

Newly, nitrogen was produced in the form of NF by coating urea with hydroxyapatite, which resulted in a slow release of nitrogen to plants (Kottegoda et al., 2017). They have also shown that a nano-hybrid of urea (for example, a modified form of hydroxyapatite) in paddy rice fields can release $\mathrm{N}$ twelve times slower than synthetic urea and increase the grain yield by $50 \%$. Frequent uses of synthetic P fertilizers made from urea. Kottegoda et al., (2017) also show low absorption efficiency and high stabilization rates in soils, while nano composites made with $\mathrm{P}$ can reduce nutrient loss through direct absorption by plants (Dwivedi et al., 2016). For example, it was found that the use of porous nano materials such as chitosan and zeolite significantly improve the absorption efficiency by controlling the release as needed and reducing nitrogen loss (Abdulaziz et al., 2016).

Finally, the rates and costs of NFs applications are usually lower than conventional fertilizers because of NFs are used in smaller amounts (León-Silva et al., 2018).

\section{Important characters of nano-fertilizers for facilitate high values of nutrient use efficiency and reducing the nutrients leaching.}

The specific properties of nano fertilizers that make them more useful than synthetic fertilizers are shown in Figure 2 (Singh and Kumar, 2017). One of its most significant properties is its ability to penetrate plants due to its small particle size $(<100 \mathrm{~nm})$ when applied to leaf or soil transition (Liscano et al., 2000). NFs with large surface areas will give maximum response and higher nutrients availability and nutrient use efficiency (Siddiqi and Husen, 2017).

NFs are also water-soluble and can improve nutrients distribution in the soil and increase plant nutrients availability, while conventional fertilizers that have low solubility due to the large size of the particles and to the adsorption and fixation by soil particles. In NPs, fertilizers are encapsulated to increase their absorption and nutrients availability for plants and so decrease their overall demand (Chhipa, 2017). For example, it is possible to provide plants with plenty of nutrients during the entire growth phase using zeolite-based moisturizers. In addition, the slow and targeted release of nutrients from NF reduces its toxicity to plants (Sohair et al., 2018) and reduces nitrogen losses through leaching, fixation, volatilization, and de nitrification as well as salt accumulation in the soil. 


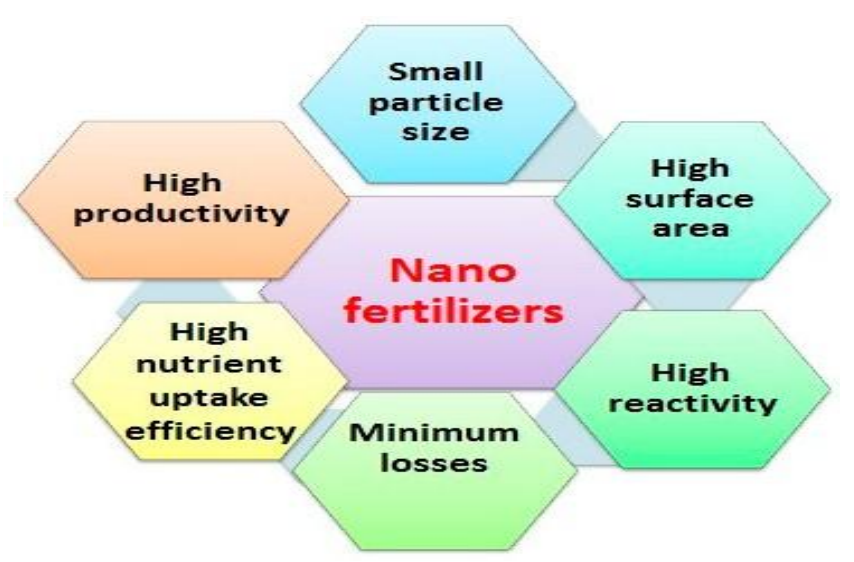

Fig. 2: Advantages of NFs or/and NPs.

\section{Macronutrient (NPK) nano-fertilizers (NFs) and their effects on crop production}

Fertilizers are essential to plant development as increasing growth and crops yield and quality, for achieving the plant requirements. Plants need macronutrients, as nitrogen, phosphorus, and potassium, in large quantities (Czymmek et al., 2020). Since most of these nutritional supplements are not consumed effectively by plants, a farmer loses large amounts of fertilizer to partially remediate their low value of NUE, with a known unfriendly impact on soil, water, and the environment (Chhipa, 2017).

The use of NFs can increase the fertilizers use efficiency, improve the yield and quality of crop and reducing the negative effects of counterfeit compost on more sustainable cultivation (Seleiman et al., 2020b). NFs release the nutrients directly into the plants root zone so diminishing rapid chemical changes of nutrients in the soil, which in turn, reduces nutrient losses. Depending on the substance or carrier, different types of NFs are produced, for example in hydroxyapatite nano particles, zeolites, permeable nanoparticles made of silicon dioxide, nitrogen, copper, zinc, silicon dioxide, carbon, and polymeric nanoparticles (Guo et al., 2018).

\section{Nitrogen Nano-Fertilizers (NNFs)}

Nitrogen $(\mathrm{N})$ is the most important plant mineral and basic part of many amino acids, proteins, DNA, ATP and chlorophyll, as well as the structural units of cells. Most of the metabolic functions and regulatory pathways in plants depend on enough amounts of nitrogen. Plants absorb $\mathrm{N}$ in $\mathrm{NO}_{3}{ }^{-}$ and $\mathrm{NH}_{4}{ }_{4}^{+}$form (Seleiman et al., 2020b). The high volatility and leaching rate occurring during and at once after field application is one of the key drawbacks of synthetic nitrogen fertilizers. NNFs used for a continuous addition of nitrogen with a slow rate to reduce these losses. Manikandan and Subramanian (2016) used zeolite-urea nanofertilizers for corn and showed higher uptake of nitrogen, stronger growth, and better grain yield with good quality comparing with conventional fertilizer of urea. Mahmoodi et al., (2017) found that as using NNF for starflower oil crop, a better growth parameters and higher essential oil yield were obtained. Urea-modified zeolite was also found to increase the yield of soybean seeds compared to synthetic fertilizers (Liu and Lal (2015). As well as nano nitrogen as it is or in chelation form was more efficient in enhancing potatoes yield and diminishing losses of nitrate by leaching (Zareabyaneh and Bayatvarkeshi, 2015). On the other hand, Ha et al., (2018) applied an integrated NPK coated nana fertilizer to seedlings of coffee and showed that such fertilizer reaching the absorption values of NPK, growth parameters as leaves numbers and photosynthetic plant area of whole coffee plants to best values. As a result, in comparing with control treatment, the plants contents of NPK increased by $17.1 \%, 16.3 \%$, and $67.5 \%$, while the total chlorophyll and net rate of photosynthesis increased up to $30.7 \%$ and $71.7 \%$, respectively. Likewise, Gomaa et al., (2018) showed that a foliar spray rate of $5.0 \mathrm{~kg} /$ ha nano-particle fertilizer (NPK) resulted in the highest values for straw yield $(7.5 \mathrm{t} / \mathrm{ha})$ and grain yield $(5.4 \mathrm{t} / \mathrm{ha})$, crop factor $(42.1 \%)$ and grain protein (10.1\%) compared to other rates. Then it can be recommended by using NNFs for improving crops productivity due to their good performance in increasing the nutrient absorption with decreasing losses in addition to their slow-release character along the growth periods. 


\section{Phosphorus Nano-Fertilizers (PNFs)}

Phosphorus is one the most important macronutrients after $\mathrm{N}$ which plant needed for best plant development. It is an essential part of ATP, ADP, phospholipids, and sugar phosphate energy transfer molecules and plays an important role in processes such as photosynthesis and respiration and DNA biosynthesis (Soliman et al., 2016). Various factors influence plant productivity such as root length and germination, plant viability, disease resistance, reproductive buds' number are affected by phosphorus availability (Preetha and Balakrishnan, 2017). However, phosphorus is not readily available in synthetic fertilizers because of its slow release and high fixation in the soil. A recent study showed that up to 40-50 days after application, PNFs can gradually transfer phosphorus, while common synthetic phosphorus fertilizers transfer them during 8-10 days of use. Then, it has been state that using of PNFs or P- zeolite as slow-release fertilizers have a potential to increase the phosphorus use efficiency for many crops. It was also found that bio safe nano-fertilizer, as a source of phosphorus was significantly increasing many times over, the total quantities of biomass and yield and reaching the best quality, also leads to higher phosphorus use efficiency (Patra et al., 2013). Similarly, soybean growth improved with the use of nano-sized hydroxyapatite (nHA) and resulted in seed yields of 20.4 percent higher than that of the slow-release conventional phosphorus fertilizer. Similarly, Soliman et al., (2016) obtained stimulation in growth of Adansonia digitations plants and their antioxidant contents after foliar sprayed with nano hydroxy apatite. So, application of PNFs has be a suitable way in smart agriculture for enhancing the crops productivity.

\section{Potassium Nano- Fertilizers (KNFs)}

KNFs it is playing an important regulatory role in all the physiochemical functions of plants. K is involved in opening the stomata of the plant, Photosynthesis, translocation of photosynthates, protein synthesis, ionic balance, water relationships, and the activation of more than 60 enzymes (Preetha and Balakrishnan, 2017).In this concern, different root, vegetative and fruit growth parameters, as well as crop yield and its quality are negatively affected by the lack of potassium. However, potassium fertilizer's overall application efficiency is typically between 30 percent and 50 percent (Battaglia et al., 2018), which means that up to 50-70 percent of the potassium fertilizer applied may be lost, causes decreases in crop net income and lowering soil fertility (Czymmek et al., 2020). Kubavat et al., (2020) showed that applying of KNFs as a slow-release formula, can minimize the potassium losses in the soil, and at the same time keeping the potassium supply of the plants for more time. Li et al., (2010) found that zeolite-based K nano-fertilizers enhanced hot pepper yield and their components beside increasing potassium and chlorophyll contents. Afifi et al., (2019) also found that the use of nano K-fertilizers significantly affected growth promotion and increased both seed yield and oil content in peanuts by $91.5 \%$ in the seed yield, $120 \%$ in the pod yield and $99.8 \%$ in oil yield / acre comparing to control. These positive effects of nano-potassium fertilizers on growth and yield were due to releasing nutrients when needed and controlling the release of chemical fertilizer for regulation of plant growth and increased target activity. In addition to that KNFs can preserve soil fertility and improving the quality of water irrigation via minimizing amount of potassium losses into soil, hence, enhancing many physiological process and crops yield traits.

\section{Micronutrient (Zn, Fe, Mn, Cu, B) Nano-Fertilizers (NFs) and their effects on plants}

Although the plant's need for micronutrients is much less than for macronutrients, they have an important and influential role on crop productivity (Seleiman et al., 2020b). The production of micronutrients in the form of nanoparticles, it increases their solubility with good distribution of elements in the soil in addition to minimizing the adsorption and fixation of elements by colloidal part or lime of soil .All of this was reflected in the increased nutrients validity and thus on the improvement and increase of the crop yield and its quality.

\section{Zinc Nano-Fertilizers (Zn NFs)}

Since zinc is a structural cofactor for many proteins and enzymes, it has a significant effect on plant growth through zinc feeding. It is also taking place in auxins regulation, proteins metabolism of, carbohydrates biosynthesis and plant defense against pathogens and environmental stresses (Broadley et al., 2007). In modern agriculture, $\mathrm{ZnNFs}$ are widely used in the form of $\mathrm{ZnO}$ due to their more efficient and cheapest than synthetic fertilizers and it can be also mixed with soil, seed treatment and 
leaf spraying (Seleiman et al., 2020a). Studies have shown that applying ZnONFs increased seeds germination, growth of seedlings, yield and their quality and improved protein and sugar contents, and antioxidant function of cabbage and tomato crops (Singh et al., 2013). Yusefi-Tanha et al., (2020)treated soybeans with various compounds of zinc such as ZnONP-38 spherical, flower- shaped $\mathrm{ZnONP}-59$ and bar-shaped $\mathrm{ZnONP}-500$ in nanometer scale, and $\mathrm{ZnCl}_{2}$, at concentrations of $(0,40,80$, $160,400 \mathrm{mg} \mathrm{Zn} / \mathrm{kg}$ soil), the results showed significant increases in seed yield in the following order:ZnONP-38 $>\mathrm{ZnONP}-59>\mathrm{ZnONP}-500>\mathrm{ZnCl}_{2}$, and same trend as concentrations increases till $160 \mathrm{mg} \mathrm{Zn} / \mathrm{kg}$ soil. Similarly, Moghddasi et al., (2017) added ZnONPs at rate of $100 \mathrm{mg} / \mathrm{kg}$ to cucumber plants and showed that plants absorbed more of $\mathrm{ZnO}$ from $\mathrm{ZnONFs}$ than their artificial one. Likewise, Tarafdar et al. (2014) and Monreal et al., (2016) showed increases in growth parameters (stem, leaf area, fresh and dry weights) in addition to significant effects on yield and protein content of rice, corn, sugar cane, sunflower, and potatoes crops .In short, zinc oxide in the form of ZnNFs are the preferable nano fertilizer applied in smart agriculture, either as spray foliar application or adding to the soil or adding at preparation of seed. Zn NFs promote seed germination, zinc absorption by roots and translocation through stem, growth, yield, and harvest quality of many crops. It is less expensive than conventional zinc fertilizer.

\section{Iron Nano-Fertilizers (FeNFs)}

Iron is an essential element that is associated with many metabolic functions in the plant. While plants require small amounts of iron for development, iron deficiency negatively affecting plant physiological functions and metabolism and reduces the yield of plants (palmqvist et al., 2017). The availability of iron is typically high in well-aerated soils. However, in these soils, at neutral $\mathrm{pH}$ levels, iron usually forms insoluble iron compounds, making them inaccessible to plants. Therefore, fertilizers fortified with iron will increase the supply of iron to plants. Compared to control and/or synthetic sources of iron, various researches reported that Fe NFs improve seed germination and promote the crop growth parameters. Srivastava et al., (2014) reported that iron pyrite NPs increased spinach growth. Askary et al., (2016) applied different concentrations of $\mathrm{Fe}_{2} \mathrm{O}_{3} \mathrm{NFs}(0,510$ 20, 30, and $40 \mathrm{mM}$ ) on rose periwinkle, and observed also that Fe NFs promoted many growth parameters, chlorophyll and protein levels compared to control. Nadi et al., (2013) examined the effect of spraying leaves with iron at the nanoscale (i.e., control, iron $2 \mathrm{~g} / 1$, nano iron at 2.4 and $6 \mathrm{~g} / \mathrm{l}$ ) on yield components and bean yield. In three different time periods (i.e., spray before and at flowering). They showed that the highest seed yield $\left(467.7 \mathrm{~g} / \mathrm{m}^{2}\right)$ was found belong to spraying nano iron $(6 \mathrm{~g} /$ 1) during the flowering period and the lowest $\left(352.7 \mathrm{~g} / \mathrm{m}^{2}\right)$ was for control. Raju et al., (2016) observed that foliar applied of $\mathrm{FeSO}_{4} \mathrm{NPs}$ led to a longer root length and highest fresh weight and chlorophyll content and protein levels of green grammes compared to the control. In conclusion, $\mathrm{Fe}-$ NFs can be ideal alternative sources, especially in iron-deficient soils.

\section{Manganese Nano-Fertilizers (MnNFs)}

Manganese is involved in ATP and protein and fatty acids biosynthesis, photosynthesis, and metabolism of nitrogen (Palmqvist et al., 2017). Manganese can, however, be toxic to many plants, depending on the chemical properties of the acidic soil. Manganese helps plants to cope with different stresses. Studies have shown that the use of manganese enhances wheat, maize, sugar, soybeans, and beans' growth and productivity (Fageria, 2001 and Dimkpa \& Bindraban, 2016). Studies of manganese nano-fertilizers in different crops have shown that the manganese Nano-processing can increase root and sprout growth of mung bean by 52\%. Compared with control $\left(\mathrm{MnSO}_{4}\right)$ (Pradhan et al., 2013). Manganese treatments also increased eggplant yield by $22 \%$ and the length of the lettuce roots compared to the control (Mn ions), (Liu et al., 2016). At the physiological point of view, Mn NFs associated with chlorophyll binding protein which results in an increase in electron transport chain activity, so enhancing efficiency of the photosynthesis process (Pradhan et al., 2013). So, application of Mn NFs gave a high rate of nitrogen assimilation and metabolism comparing with conventional Mn fertilizer.

\section{Copper Nano Fertilizers (Cu NFs)}

Copper is a constituent of regulatory proteins that takes part in photosynthesis and respiration processes of plants and is an antioxidants cofactor such as superoxide dismutase and ascorbate 
oxidase. Copper deficiency leads to various disorders; necrosis, stunted growth, low numbers of seeds, grains, fruits, and finally low crops yield (Rai et al., 2018). Application $\mathrm{Cu}$ NFs enhancing growth parameters and yield of different crops due to its higher of surface area, solubility, and reactivity (Hong et al., 2018). Studies on soybeans and chickpeas showed that the field application of $\mathrm{Cu}$ ONFs activates the seed germination and root growth (Adhikari et al.2012). Likewise, soybean seeds treated with nanocrystalline powders of $\mathrm{Cu}(40-60 \mathrm{~nm})$ had $65 \%$ increases in germination rate, comparing to 55\% of a control sample (zero NF) (Ngo et al.2014). Otherwise, various applied rates of CuNFs increased the growth and yield of wheat due to increments in leaf area, contents of chlorophyll, grains numbers per spike, and grain weight. Furthermore, Nair and Chung (2014), added CuNFs at rate of $5 \mathrm{mg} / \mathrm{L}$ to Arabidopsis thaliana, and found that an increment in flavonoid contents, Sulphur assimilation, and the biosynthesis of proline and glutathione (Nair and Chung, 2014). Conversely, CuNF application negatively affected the growth of lettuce (Olkhovych et al., 2016) and decreased fruit firmness in cucumber plants (Hong et al., 2016). It concluded that $\mathrm{Cu}$ NFs can improved biochemical and yield traits but must be take into consideration with their application rate.

\section{Boron Nano-Fertilizers (BNFs)}

Boron has important roles in pollen grains and tubes elongation, formation of cellular walls, photosynthetic products transfer from leaves to active sites, and increases in flowers and fruits yields (Davarpanah et al., 2016). Ibrahim et al. (2019) sprayed 90 and $180 \mathrm{mgL}^{-1}$ of BNFs on mung bean crops, and they showed increases in pods number and seed yield compared to a control .As well as Genaidy et al., (2020) foliar sprayed BNFs and Zn NFs at rates of 20 and $200 \mathrm{mg} \mathrm{L}^{-1}$ on olive trees, respectively, and they produced a highest fruits number with a highest seed oil content. Comparably, applying of boron nano fertilizer, Davarpanah et al., (2016) found an increase in both pomegranate fruits number and its yield at the application rate of $34 \mathrm{mg}$ boron per tree. Taherian et al., (2019) applied BNFs to an alfalfa fodder crop grown on calcareous soil; they are cutting a maximum yield with valuable forage quality.

\section{Zeolite-Based Nano-Fertilizers (Nano Porous Zeolite)}

Zeolite and nanoporous zeolite used as a slow-release fertilizer in farming (Gholizadeh, 2008 and Ramesh et al., 2010). It normally helps in slow release of the fertilizer to the plant, this way of doing makes the plant to grab entire amount of nutrients from the applied fertilizer rather than the minimal uptake. Since it has larger surface area and many particles can fit in it and are released whenever the plant needs (Naderi and Danesh-Shahraki, 2013). The zeolite was made with nanoscale particles using a ball mill, then centrifuged and stirred with $50 \mathrm{ml}$ of $1.5 \mathrm{M} \mathrm{CaSO}_{4}$, filtered, and washed with de ionized water then air dried. The solids: liquid ratio was kept at 1:10 for the purpose of synthesis (Selvapreetha and Sharmila, 2014).

Nitrogen fertilizers are important, but they can cause significant damage to the plants and surrounding areas due to their high solubility. So, a nano porous zeolite shown in (Fig.3) with urea of higher water solubility was used as a source of nitrogen without exposing the plants or the environment to any harm, in addition to enhancing absorption of urea with increasing its controlled released efficiency (Manikndan and Subramanian, 2013).

This zeolite also helps to maintain soil moisture and helps in nutrients extraction from the soil (Ram et al., 2014).The nano composites were synthesized using nano sheets and zeolites from corn as a slow-release fertilizer that released nitrogen in available form up to 45-49 days (Sharmila, 2010). Zeolite and nano zeolite are used as slow-release fertilizers in agriculture (Gholizadeh, 2008 and Ramesh et al., 2010). The use of urea- zeolite, potassium sulfate- and calcium -hydroxyl apatite as slow-releasing nano-fertilizers increased the availability for 60 days (Kottegoda et al., 2011). The clay polymer nanocomposite compound using crystalline and amorphous components of soil clay increased the biomass yield (Sarkar, 2011). 


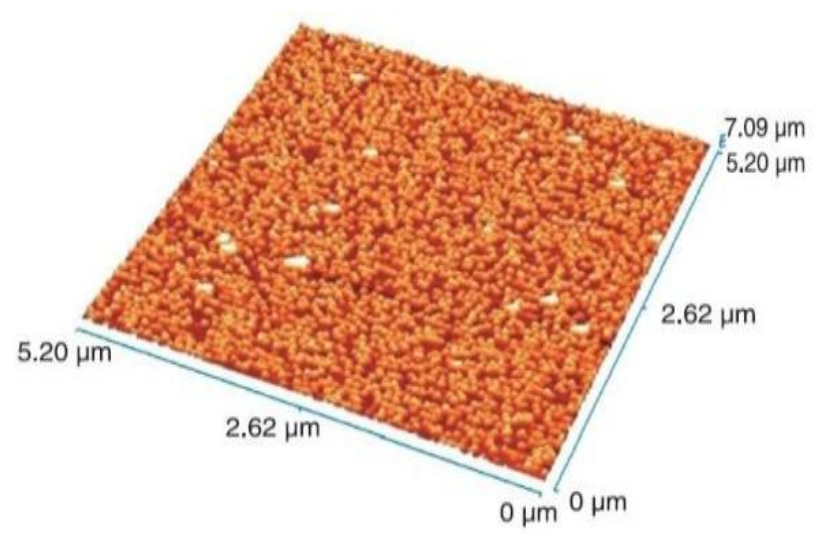

Fig. 3: Nitrogen loading in the sheet of Zeolite.

\section{Carbon Nanotube}

Tubes are shown in cylindrical tubes (Fig. 4) and consist of carbon molecules with various wall construction numbers. The strong Van der Waals force keeps these carbon particles in place, making them ideal for particle packing, filtration, energy storage, monitoring of the atmosphere and much more.

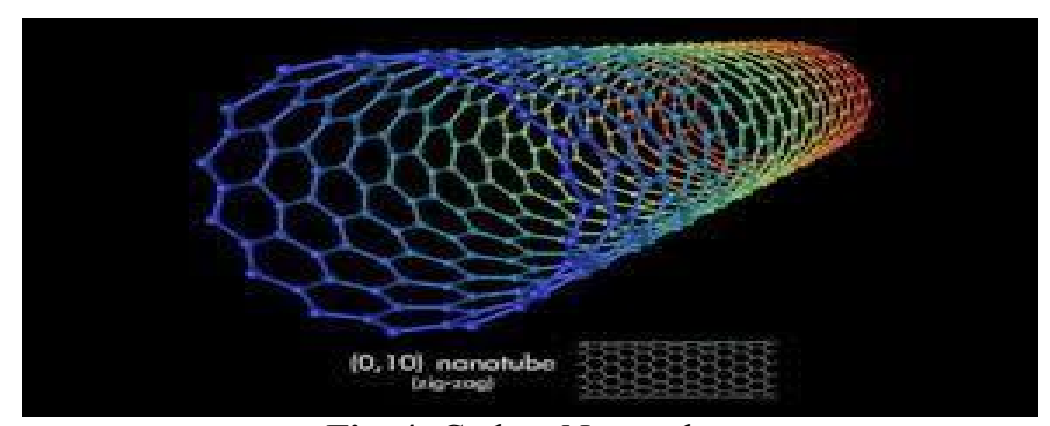

Fig. 4: Carbon Nano tubes

These multi-walled carbon nanotubes have a beneficial role in agriculture for increasing growth rate, water consumption and absorption of important soil nutrients.

Different yields were observed with the introduction of different range of carbon nano tubes when an external Fe supplement, taking calcium ions into account for balancing, stabilized the yield was maintained. (Tiwari et al., 2013).

To crops such as corn, wheat, peanuts and garlic, application of this Carbon Nano tube at a rate of $50 \mu \mathrm{g} / \mathrm{ml}$ gave best results in increasing length of root and shoot, time of seed germination, promoting growth and a well-developed root system in addition to help plants to keep their water content and significantly increase their production rate (Anita and Rao, 2014). On the other hand, nano carbon is a new material with special physicochemical properties that stimulates plant growth, improves the soil environment, and promotes the metabolism of plant growth (Liu et al., 2008 and Xiao et al., 2008). The nano carbon scale is ranged from $5-80 \mathrm{~nm}$ with a low flash point and nonconductive modified carbon and has a quantum tunnel, small size, surface, and interface effect, etc., which the aggregate materials did not have. Other studies show that Carbon Nano tubes fertilizers significantly increased use efficiency of fertilizers and yield of winter wheat (Liu et al., 2008). Using of Carbon Nano tube in rice crop as a slow-release fertilizer increased its chlorophyll content, grain yield and the nitrogen use efficiency (Wu et al., 2010).

\section{Conclusions}

An increase in food production occurs due to uses new and innovative fertilizers using nanotechnology to face the increase in population, from the perspective of sustainable agriculture. As part of smart plant production systems in sustainable agriculture, NFs have potential because they have wide areas and slow and steady nutrient release. For use in modern agriculture, these promising 
properties make it very suitable. The use of non-food products can improve productivity in agriculture. By intelligently distributing active ingredients, applying NFs will help in minimize fertilizer amounts, maximize absorption of nutrients and increasing nutrients use efficiency values, and reduce fixation, volatilization and leaching of nutrients after applying of fertilizers. In addition, using of NFs and nano sensor seed coatings will minimize both of agricultural production costs and environmental problems. In 40-50 days, nano fertilizers can release their nutrients, while in 4-10 days only synthetic fertilizers do so. As a result, after field application via leaching and volatilization, conventional fertilizers, especially urea, lose fifty percent of its nitrogen content. Research has also shown that NFs release nutrients 12 times more slowly comparing to traditional fertilizers and so increase crop yields and quality characteristics. Future studies should focus in detail on source, type, rate, use efficiency, and bioavailability of the various NFs or NPs used in agricultural production. Additionally, synthetic, or green synthetic nano fertilizers should be examined to increase yields in sustainable agriculture.

\section{References}

Abdel-Aziz, H.M.M., M.N.A. Hasaneen, and A.M. Omer, 2016. Nano chitosan-NPK fertilizer enhances the growth and productivity of wheat plants grown in sandy soil. Span. J. Agric. Res., 14, e0902.

Adhikari, T., S. Kundu, A.K. Biswas, J.C. Tarafdar, A.S. Rao, 2012. Effect of copper oxide nano particle on seed Germination of selected crops. Journal of Agricultural Science and technology .ISSN 1939-1250.A2 (2012):815-823.

Afify, R.R., S.S. El-Nwehy, A.B. Bakry and M.E. Abd El-Aziz (2019). Response of peanut (Arachis hypogaea L.) crop grown on newly reclaimed sandy soilto foliar application of potassium nanofertilizer. Middle East J. Appl. Sci., 9(1): 78-85.

Anita, S. and D.P. Rao, 2014. Enhancement of seed germination and plant growth of wheat, maize, peanut, and garlic using multi walled carbon nano tubes, Eur. Chem. Bull, 3(5): 502-504.

Askary, M., M. Amirjani, and T. Saberi, 2016. Comparison of the Effects of Nano-Iron Fertilizer with Iron-Chelate on Growth Parameters and Some Biochemical Properties of Catharanthus Roseus. Journal of Plant Nutrition 40(7). DOI: 10.1080/01904167.2016.1262399

Battaglia, M.L., G. Groover, and W.E. Thomason, 2018. Harvesting and Nutrient Replacement Costs Associated with Corn Stover Removal in Virginia; Virginia Cooperative Extension Publication: Ettrick, VA, USA, CSES-229NP.

Broadley, M.R., P.J. White, J.P. Hammond, I. Zelko, and A. Lux, 2007. Zinc in plants. New Phytologist. 173(4):677-702.

Brunnert, I., P. Wick, S. Manserp, R.N. Grass, L.K. Limbach A. Bruinink and W.J. Stark, 2006. Environmental Science \& Technology, 40: 4374-4381.

Chhipa, H., 2017. Nano-fertilizers and nanopesticides for agriculture. Environ. Chem. Lett., 15: 1522.

Chinnamuthu, C.R. and P.M. Boopati, 2009. Nanotechnology and agroecosystem. Madras Agric J., 96:17-31.

Cui, H.X., C.J. Sun, Q. Liu, J. Jiang, and W. Gu, 2010. Applications of nanotechnology in agrochemical formulation, perspectives, challenges, and strategies. International conference on Nano Agri, Sao Pedro, Brazil, 20-25.

Czymmek, K., Q. Ketterings, M. Ros, M. Battaglia, S. Cela, S. Crittenden, D. Gates, T. Walter, S. Latessa, and L. Klaiber, 2020. The New York Phosphorus Index 2.0. Agronomy Fact Sheet Series. Fact Sheet \#110; Cornell University Cooperative Extension: New York, NY, USA.

Davarpanah, S., A. Tehranifar, G. Davarynejad, and J. Abadia, 2016. Effects of foliar applications of zinc and born nano-fertilizers on pomegranate fruit yield and quality. Scientia Horticulturae, 210:57-64.

DeRosa, M.C., C. Monreal, M. Schnitzer, R. Walsh, and Y. Sultan, 2010. Nanotechnology in fertilizers. Nat Nanotechnol, 5:91.

Diatta, A.A., W.E. Thomason, O. Abaye, T.L. Thompson, M.L. Battaglia, L.J. Vaughan, M. Lo, and J.F.D.C.L. Filho, 2020. Assessment of nitrogen fixation by Mung bean genotypes in different 
soil textures using 15N natural abundance method. J. Soil Sci. Plant Nutr. 20: 2230-2240.

Dimkpa, C.O. and P.S. Bindraban, 2016. Fortification of micronutrients for efficient agronomic production: A review. Agron. Sustain. Dev., 36: 1-26.

Dwivedi, S., Q. Saquib, A.A. Al-Khedhairy, and J. Musarrat, 2016. Understanding the role of nanomaterials in agriculture. In Microbial Inoculants in Sustainable Agricultural Productivity; Springer Science and Business Media LLC: Heidelberg, Germany, 271-288.

Fageria, V.D., 2001. Nutrient interactions in crop plants. J. Plant. Nutr., 24: 1269-1290.

FAO, Food and Agriculture Organization of the United Nations, 2020. FAO Statistics Division. Available online: http://www.fao.org/faostat/en/\#data/QC/visualize (accessed on 1 November (2020).

Genaidy, E.A.E., N. Abd-Alhamid, and L.F. Hagagg, 2020. Effect of foliar application of boron trioxide and Zinc Oxide nanoparticles on leaves chemical composition, yield and fruit quality of Olea europaea L.cv. Picual.bulitin of the National Research Centr., 44 (106):2-12.

Gholizadeh, A., 2008. Zeolitic slow-release fertilizer: A brief review. Iran International Zeolite Conf. (IIZC'08) Tehran-Iran.1-2.

Glass, A.D.M., 2003. Nitrogen-use efficiency of crop plants: Physiological constraints upon nitrogen absorption. Critical Reviews of Plant Sciences, 22:453-470.

Gomaa, M.A., F.I. Radwan, E.E. Kandil and M.A.F. Al-Msari, 2018. Response of some Egyptian and Iraqi wheat cultivar to mineral and nano-fertilization.Egypt. Acad. J. Biolog. Sci., 9(1):19 - 26.

Guo, H., J.C. White, Z. Wang, and B. Xing, 2018. Nano-enabled fertilizers to control the release and use efficiency of nutrients. Curr. Opin. Environ. Sci. Heal., 6: 77-83.

Ha, N.M.C., T.H. Nguyen, S.L. Wang, and A.D. Nguyen, 2018. Preparation of NPK nanofertilizer based on chitosan nanoparticles and its effect on biophysical characteristics and growth of coffee in green house. Res. Chem. In termed., 45: 51-63.

Hong, J., L. Wang, Y. Sun, L. Zhao., G. Niu, W. Tan, C.M. Rico, J.R. Peralta-Videa, and J.L. GardeaTorresdey, 2016. Foliar applied nanoscale and microscale $\mathrm{CeO}_{2}$ and $\mathrm{CuO}$ alter Cucumber fruit quality .Science of the Total Environment.563-564, 904-911.

Husen, A. and M. Iqbal, 2019. Nanomaterials and Plant Potential; Springer: Cham, Switzerland.

Ibrahim, K.A., M.Y. Naz, S. Shukrullah, and A. Sulaiman, 2019. Controlling nitrogen pollution via encapsulation of urea fertilizer in cross-linked corn starch. BioResources, 14(4):7775-7789.

Kahrl, F., Y. Li, Y. Su, T. Tennigkeit, A. Wilkes, and J. Xu, 2010. Greenhouse gas emissions from nitrogen fertilizer use in China. Environ. Sci. Policy, 13: 688-694.

Kottegoda, N., I. Munaweera, N. Madusanka, and V.A. Karunaratne, 2011. Green slow-release fertilizer composition based on ureamodified hydroxyapatite nanoparticles encapsulated wood. Curr. Sci., 101(1):73-78.

Kottegoda, N., C. Sandaruwan, G. Priyadarshana, A. Siriwardhana, U.A. Rathnayake, D.M.B. Arachchige, A.R. Kumarasinghe, D. Dahanayake, V. Karunaratne, and G.A.J. Amaratunga, 2017. Urea-hydroxyapatite nanohybrids for slow release of nitrogen. ACS Nano, 11: 12141221.

Kubavat, D., Trivedi, K., Vaghela, P., Prasad, K., Vijay Anand, G.K., Trivedi, H., Patidar, R., J. Chaudhari, B. Andhariya, and A. Ghosh, 2020. Characterization of a chitosan-based sustained release nanofertilizer formulation used as a soil conditioner while simultaneously improving biomass production of Zea mays L. Land Degrad. Dev., 31: 2734-2746.

León-Silva, S., R. Arrieta-Cortes, F. Fernández-Luqueño, and F. López-Valdez, 2018. Design and Production of Nano-fertilizers. In Agricul- tural Nanobiotechnology; Springer Science and Business Media LLC: Cham, Switzerland, 17-31.

Liscano, J.F., C.E. Wilson, R.J.Jr. Norman, and N.A. Slaton, 2000. Zinc Availability to Rice from Seven Granular Fertilizers; Arkansas Agricultural Experiment Station: Fayetteville, CA, USA, Volume 963.

Li, J.X., C.D. Wee, and B.K. Sohn, 2010. Growth response of hot pepper applicated with ammonium $\left(\mathrm{NH}_{4}{ }^{+}\right)$and Potassium $\left(\mathrm{K}^{+}\right)$- Loaded Zeolite. Korean J. Soil Sci. Fert., 43(5): 619-625.

Liu, J., Y.D. Zhang, and Z.M. Zhang, 2008. Study on application of nanometer biotechnology on the yield and quality of winter wheat. Journal of Anhui Agri. Sci., 36 (35):15578-15580.

Liu, R. and R. Lal, 2015. Synthetic apatite nanoparticles as a phosphorus fertilizer for soybean (Glycine max). Sci. Rep., 4, srep05686. 
Liu, R., H. Zhang, and R. Lal, 2016. Effects of stabilized nanoparticles of copper, zinc, manganese, and iron oxides in low concentrations on Lettuce (Lactuca sativa) seed germination: Nanotoxicants or nanonutrients? Water Air Soil Pollut., 227: 1-14.

Mahmoodi, P., M. Yarnia, R. Amirnia, A. Tarinejad and H. Mahmoodi, 2017.Comparison of the Effect of Nano Urea and Nano Iron Fertilizers with Common Chemical Fertilizers on Some Growth Traits and Essential Oil Production of Borago Officinalis L. Agricultural Research \&Technology, 2(2):555-585.

Manikandan, A. and K.S. Subramanian, 2013. Fabrication and characterisation of nano porous zeolite-based N fertilizer. Afri. J. Agri. Res., 9 (2):276-284.

Manikandan, A. and K.S. Subramanian, 2016. Evaluation of Zeolite Based Nitrogen Nano-fertilizers on Maize Growth, Yield and Quality on Inceptisols and Alfisols. Inter. J. of Plant \& Soil Sci., 9(4): $1-9$.

Melani, N., M.J. McLaughlin, S.P. Stacey, J.K. Kirkby, G.M. Hettiarachchi, D.G. Beak, and G. Cornelis, 2012. Dissolution kinetics of macronutrient fertilizers coated with manufactured zinc oxide nanoparticles. J Agric Food Chem, 60:3991-3998

Miransari, M., 2011. Soil microbes and plant fertilization. Appl Microbiol Biotechnol., 92:875-885.

Moghaddasi, S., A. Fotovat, A.H. Khoshgoftarmanesh, F. Karimzadeh, H.R. Khazaei, and R. Khorassani, 2017. Bioavailability of coated and uncoated $\mathrm{ZnO}$ nanoparticles to cucumber in soil with or without organic matter. Ecotoxicol. Environ. Saf., 144: 543-551.

Monreal, C.M., M. DeRosa, S.C. Mallubhotla, P.S. Bindraban, and C. Dimkpa, 2016. Nanotechnologies for increasing the crop use efficiency of fertilizer-micronutrients. Biol. Fertil. Soils, 52: 423-437.

Naderi, M.R. and A. Danesh-Shahraki, 2013. Nano-fertilizers and their roles in sustainable agriculture, Inter. J. Agri. Crop Sci., 5(19):2229-2232.

Nadi, E., A. Aynehb and, M. Mojaddam, 2013. Effect of nano-iron chelate fertilizer on grain yield, protein percent and chlorophyll content of Faba bean (Vicia faba L.). Int. J. of Biosci., 3 (9) : 267-272.

Nair, P.M.G. and M. Chung, 2014. Impact of copper oxide nanoparticles exposure on Arabidopsis thaliana Growth, root system development, root lignifications and molecular level changes. Environmental Science and Pollution Research.DOI:10.1007/s11356-014-3210-3. 2014 Nov; 21(22):12709-12722.

Nair, R., S.H. Varghese, B.G. Nair, T. Melawi, Y. Yoshida, and D.S. Kumar, 2010. Nanoparticulate material delivery to plants. Plant Sci., 179:154-163.

Nel A., T. Xia, L. Madler and N. Li, 2006. Science, 311: 622-627.

Ngo, Q.B., T.H. Dao, H.C. Nguyen, X.T. Tran, T. Van Nguyen, T.D. Khuu, and T.H. Huynh, 2014. Effects of nanocrystalline powders $(\mathrm{Fe}, \mathrm{Co}$, and $\mathrm{Cu})$ on the germination, growth, crop yield and product quality of soybean (Vietnamese species DT-51). Adv. Nat. Sci. Nanosci. Nanotechnol., $5,015016$.

Ombodi, A. and M. Saigusa, 2000. Nanotechnology for Agriculture: Advances for Sustainable Agriculture. Book.edited by Deepak G Panpatte, Yogeshvari K Jhala.

Olkhovych, O., M.Volkogon, N. Taran, L. Batsmanova, and I. Kravchenko, 2016.The Effect of Copper and Zinc Nanoparticles on the Growth Parameters, Contents of Ascorbic Acid, and Qualitative Composition of Amino Acids and Acylcarnitines in Pistia stratiotes L. (Araceae).Nanoscale Res.Lett., 23:108.

Palmqvist, N.M., G.A. Seisenbaeva, P. Svedlindh, V.G. Kessler, 2017. Maghemite nanoparticles act as nanozymes, improving growth and abiotic stress tolerance in Brassica napus. Nanoscale Res. Lett., 12:1-9.

Patra, P., S.R. Choudhury, S. Mandal, A. Basu, A. Goswami, R. Gogoi, C. Srivastava, R. Kumar, and M. Gopal, 2013. Effect sulfur and ZnO nanoparticles on stress physiology and plant (Vignaradiata) nutrition. In Advanced Nanomaterials and Nanotechnology; Springer: Guwahati, India, 301-309.

Pradhan, S., P. Patra, S. Das, S. Chandra, S. Mitra, K.K. Dey, S. Akbar, P. Palit, and A. Goswami, 2013. Photochemical modulation of biosafe manganese nanoparticles on Vigna radiata: A detailed molecular, biochemical, and biophysical study. Environ. Sci. Technol., 47: 1312213131. 
Preetha, P.S. and N. Balakrishnan, 2017. A review of nano fertilizers and their use and functions in soil. Int. J. Curr. Microbiol. Appl. Sci., 6: 3117-3133.

Qureshi, A., D. Singh, and S. Dwivedi, 2018. Nano-fertilizers: A novel way for enhancing nutrient use efficiency and crop productivity.Int. J. Curr. Microbiol. Appl. Sci., 7: 3325-3335.

Rai, M., A.P. Ingle, R. Pandit, P. Paralikar, S. Shende, I. Gupta, J.K. Biswas, and S. Silvério da Silva, 2018. Copper and copper nanoparticles: role in management of insect-pests and pathogenic microbes. Review.Nanotechnology Review, 7(4): 303-315.

Raju, D., S.R. Beedu, and U.J. Mehta, 2016. Sashidhar, R. Biogenic green synthesis of monodispersed gum kondagogu (Cochlospermum gossypium) iron nanocomposite material and its application in germination and growth of mung bean (Vigna radiata) as a plant model. IET Nanobiotechnology, 10: 141-146.

Ram, P., K. Vivek, and S.P. Kumar, 2014. Nanotechnology in sustainable agriculture: Present Concerns and future aspects, Afri J Biotechnol, 13(6): 705-713.

Ramesh, K., A.K. Biswas, J. Somasundaram, and A. Subbarao, 2010.Nano porus zeolite in farm.Current Status and issues a head.curr.Sci., 99(6):760-764.

Sarkar, S., 2011. Synthesis of clay polymer nutrient nano composites and their character risation with respect to water holding capacity and nutrient release behavior. Ph.D. Thesis, Indian Agricultural Research Institute, New Delhi.

Sasson, Y., G. Levy-Ruso, O. Toledano, and I. Ishaaya, 2007. Nanosuspensions: emerging novel agrochemical formulations. In: Ishaaya I, HorowitzAR, Nauen R (eds) Insecticide's design using advanced technologies. Springer, Berlin, 1-39.

Seleiman, M.F., M. Alotaibi, B.A. Alhammad, B. Alharbi, Y. Refay, and S.A. Badawy, 2020a. Effects of $\mathrm{ZnO}$ nanoparticles and biochar of rice straw and cow manure on characteristics of contaminated soil and sunflower productivity, oil quality, and heavy metals uptake. Agronomy, 10: 790 .

Seleiman, M.F., A. Santanen, and P. Mäkelä, 2020b. Recycling sludge on cropland as fertilizerAdvantages and risks. Resour. Conserv. Recycl., 155: 104647.

Selvapreetha, S.K.S. and R.C. Sharmila, 2014. Sorption Characteristics of Nano Zeolite Based SlowRelease Sulphur Fertilizer, Intern J Develop Res, 4 (2) : 225-228.

Sharmila, R.C., 2010. Nutrient release pattern of nano fertilizer formulations, Ph.D. Thesis, Tamil Nadu Agricultural University, Coimbatore.

Siddiqi, K.S., and A. Husen, 2017. Plant response to engineered metal oxide nanoparticles. Nanoscale Res. Lett., 12: 1-18.

Singh, M.D. and B.A. Kumar, 2017. Bio efficacy of nano zinc sulphide (ZnS) on growth and yield of sunflower (Helianthus annuus L.) and nutrient status in the soil. Int. J. Agric. Sci., 9: 37953798 .

Singh, N.B., N. Amist, K. Yadav, D. Singh, J.K. Pandey, and S.C. Singh, 2013. Zinc oxide nanoparticles as fertilizer for the germination, growth, and metabolism of vegetable crops. J. Nanoeng. Nano manufacturing, 3: 353-364.

Sohair, E.E.D., A.A. Abdall, A.M. Amany, M.F. Hossain, and R.A. Houda, 2018. Effect of nitrogen, phosphorus and potassium nano-fertilizers with different application times, methods, and rates on some growth parameters of Egyptian cotton (Gossypium barbadenseL.). Biosci. Res., 15: 549-564.

Soliman, A.S., M. Hassan, F. Abou-Elell, A.H. Ahmed, and S.A. El-Feky, 2016. Effect of nano and molecular phosphorus fertilizers on growth and chemical composition of Baobab (Adansonia digitata L.). J. Plant Sci., 11: 52-60.

Srivastava, G., C.K. Das, A. Das, S.K. Singh, M. Roy, H. Kim, N.K. Sethy, A. Kumar, R.K. Sharma, S.K. Singh, et al., 2014. Seed treatment with iron pyrite (FeS2) nanoparticles increases the production of spinach. RSC Adv., 4:58495-58504.

Taheriana, M., A. Bostanib, and H. Omidic, 2019. Boron and pigment content in alfalfa affected by nano fertilization under calcareous conditions. Journal of Trace Elements in Medicine and Biology, 53:136-143.

Tarafdar, J.C., R. Raliya, H. Mahawar, and I. Rathore, 2014. Development of zinc nanofertilizer to enhance crop production in pearl millet (Pennisetum americanum). Agric. Res., 3: 257-262. 
Tiwari, D.K., N. Dasgupta-Schubert, L.M. Villasen, J. Villegas, L. Carreto Montoya, and S.E. Borjas Garcia, 2013. Interfacing carbon nanotubes (CNT) with plants: enhancement of growth, water, and ionic nutrient uptake in maize (Zea mays) and implications for nanoagriculture, App Nano Sci, 4:577-591.

Torney, F., B.G. Trewyn, V.S.Y. Lin, and K. Wang, 2007. Mesoporous silica nanoparticles deliver DNA and chemicals into plants. Nat Nanotechnol., 2:295-300.

Usman, M., M. Farooq, A. Wakeel, A. Nawaz, S. Alam Cheema, H.U. Rehman, I. Ashraf, and M. Sanaullah, 2020. Nanotechnology in agriculture: Status, challenges, and future opportunities. Sci. Total. Environ., 721: 137778.

Wanyika, H., E. Gatebe, P. Kioni, Z. Tang, and Y. Gao, 2012. Mesoporous silica nanoparticles carrier for urea: potential applications in agrochemical delivery systems. J. Nano. Sci.Nanotechnol, 12:2221-2228.

Wu, M., H. Ruo-chao, T. Xiao-hai, W. Xiao-ling, M. Guo-hui, and T. Hai-tao, 2010. Effect of Adding Nano-carbon in slow-release fertilizer on grain yield and nitrogen use efficiency of super hybrid rice. Hybrid Rice, 4:1-5.

Xiao, Q., F.D. Zhang, Y.Y. Wang, J.F. Zhang, and S.Q. Zhang, 2008. Effects of slow/controlled release fertilizers felted and coated by nano- materials on crop yield and quality. Plant Nutri.Fert.Sci., 14(5): 951-955.

Yusefi-Tanha, E., S. Fallah, A. RostaMmnejadi, and L.R. Pokhrel, 2020. Zinc Oxide Nanoparticles (ZnONPs) as Nano-fertilizer: Improvement on Seed Yield and Antioxidant Defense System in Soil Grown Soybean (Glycine max cv. Kowsar) Sci. Total Environ.715, 136994. https://doi.org/10.1016/j.scitotenv.2020.

Zareabyaneh, H. and M. Bayatvarkeshi, 2015. Effects of slow-release fertilizers on nitrate leaching, its distribution in soil profile, N-use efficiency, and yield in potato crop. Environ. Earth Sci., 74: $3385-3393$. 